\title{
Assessment and evaluation of drug information services provided in a South Indian teaching hospital
}

\author{
Beena George, Padma G.M.Rao
}

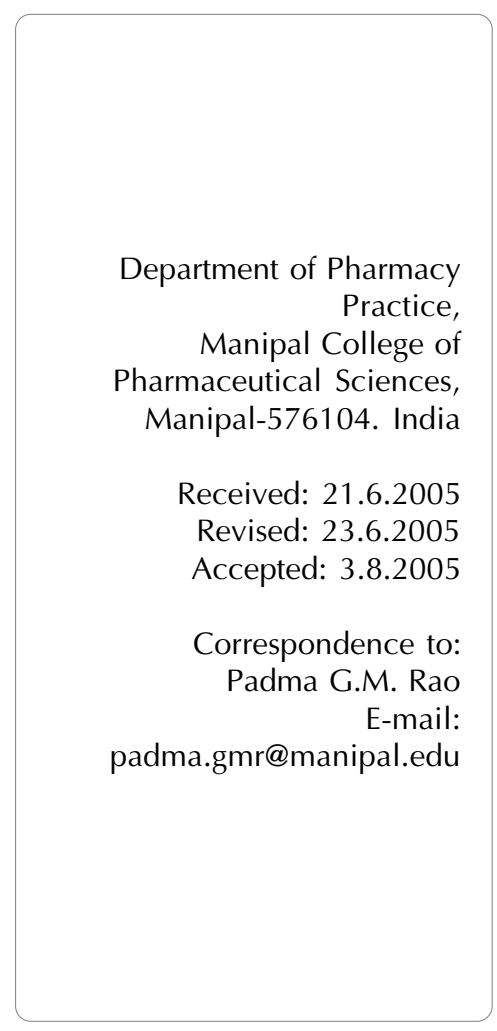

\begin{abstract}
Objective: To evaluate the various drug information queries received, and to assess the quality of services provided by the drug information center of the pharmacy practice department. Materials and Methods: The drug information queries received during ward rounds, by telephone, direct access, intranet etc. were documented in the drug information request and documentation forms prepared by the department. These forms were evaluated retrospectively for a period of 12 months, from July 2003 to June 2004, for various parameters like status of the enquirer, specialty of practice, mode of receipt of query, purpose of query, type of query etc. The quality of drug information services provided was assessed both from the receivers' as well as from the providers' perspective. The receivers' perspective was evaluated on the basis of the feedback questionnaire circulated, and the providers' perspective was evaluated by using the guidelines from the DSE/WHO seminar.

Results: A total of 666 drug information queries were received during the study period. Upon evaluation, it was found that most of the beneficiaries of the service were the physicians $(82 \%)$ and postgraduate students $(16 \%)$ of the department of medicine. The analysis of the feedback questionnaire showed that most of the enquirers $(92.5 \%)$ utilized the drug information service regularly and appreciated the quality of services provided by the drug information center. Evaluation of queries answered by the center from the providers' perspective revealed that they were within the acceptable limits of quality.

Conclusion: The drug information services provided by the pharmacy practice department of Kasturba Hospital, Manipal, caters to the need of health care professionals and eventually towards better patient care.
\end{abstract}

KEY WORDS: Drug information center, pharmacy resource, pharmacy service.

\section{Introduction}

Drug information service (DIS) is the service that encompasses the activities of specially trained individuals to provide accurate, unbiased, factual information, primarily in response to patient-oriented drug problems received from various members of the healthcare team. ${ }^{[1]}$ In the past, the number of drugs available was less and thus, the need for drug information was limited. But now, the scenario has come a long way with new modes of therapy and vast number of drug products being available. It is not humanly possible to remember such vast information on drugs. There has also been a great explosion in the number of biomedical journals published each year. Hence, it is very important to retrieve specific unbiased information. A clinical pharmacist is professionally trained and legally competent to provide drug information, which is also a key component of his/her daily activities.

In India, the concept of rational drug use is yet a long way to go. Lack of unbiased drug information and lack of time are some of the factors that makes the physicians unable to update their knowledge about drugs which have resulted in an increasing demand for independent and unbiased information about drugs for better patient care. ${ }^{[2,3]}$ It is important, to periodically evaluate the mode of functioning and quality of the services provided by the center, ${ }^{[4]}$ so that necessary modifications can be made for better functioning.

\section{Materials and Methods}

Kasturba Hospital, Manipal is a constituent of Manipal Academy of Higher Education and is a 1472-bedded tertiary care multidisciplinary teaching hospital in South India with 
198 teaching clinicians, 533 staff nurses, 38 pharmacists, and 290 postgraduate students. The drug information center is a part of the department of pharmacy practice, which was established in 2001 in the Kasturba hospital and is internationally recognized by the Australian Society for Health System Pharmacist. The centre is well equipped with trained staff and a library consisting of textbooks, National and International journals, computer and Internet facilities along with electronic databases such as IDIS and MICROMEDEX. The centre is managed by the six faculty members and 12 postgraduate students of the pharmacy practice department. The service is provided between 8 A.M and 6 P.M on all days except Sundays and public holidays.

The drug information centre caters to the needs of all health care professionals working in various departments of the hospital. Drug information services can be accessed by telephone, intranet, direct access, and also during ward rounds. Drug information request forms are also available on-line, which are to be duly filled and submitted for further processing of answer. The drug information queries are evaluated and answers are provided according to the modified systematic approach. The drug information requests and answers are documented and maintained in the drug information documentation files of the department.

Assessment and evaluation of drug information services were carried out in three steps.

The first step involved retrospective evaluation of drug information request and documentation forms for a period of 12 months, from July 2003 to June 2004. The evaluation was based on the following parameters such as professional status of the enquirer, specialty of practice, mode of receipt of query, purpose of enquiry, time frame to reply, category of question, and references used.

Secondly, the quality of services provided was assessed from the receivers perspective through a questionnaire comprising questions, pertaining to awareness, utilization, opinion, and the quality of service provided by the centre. Questionnaire was given to 40 health care professionals, who agreed to give a feedback on the service, and this included clinicians and postgraduate trainees of various units of the hospital where the clinical pharmacists were attending ward rounds. The filled questionnaires were collected after 2 days from individual respondents.

The third step involved the assessment of quality of drug information services from the provider's perspective by using the guidelines from the DSE/WHO seminar. ${ }^{[5]}$ According to these guidelines, the queries were categorized into judgmental and nonjudgmental types. Judgmental types of queries requires judgment, integration of new data with preexisting knowledge and experience, and extensive searching of secondary and tertiary references and a primary literature review. Judgmental types of queries are often patient specific. Nonjudgmental responses represent a lower degree of sophistication and do not require judgment. The aspects, which were considered during the evaluation phase, included effectiveness in obtaining the demographic data of the enquirer and collecting background information, level of understanding of the question, using the search strategy, evaluation of literature, and the response given by the provider. Queries after evaluation were scored from 1 to 5, 5 indicating that the information given was excellent; 4 very good, 3 - good, 2 - adequate and 1 - indicating that the consultation was unacceptable for use. The minimum acceptable level of rating was considered to be 3. During the study, a total of 20 queries were selected for evaluation - 10 each of the judgmental and nonjudgmental types. Two internal auditors who were well experienced in providing drug information service evaluated responses to these queries using the questionnaire. These queries were graded on the basis of the scores given by the authors.

\section{Results}

The drug information centre received a total of 666 drug information queries during the study period, with an average of 55 queries per month. A great number of queries were from the medicine department (82\%). Drug information queries were also obtained from various other departments such as surgery (3), pediatrics (14), psychiatry (3), nephrology (25), neurology (14), cardiology (7), dermatology (9), gynecology (8), urology (2), dentistry (7), nursing (4), and others (22). Clinicians utilized the service to a great extent (82\%). Postgraduate students $(16 \%)$, internees and nurses $(2 \%)$ were the other health care professionals who availed this service. Most queries were received during ward rounds (70\%). Queries were also received through telephone (20\%), intranet $(2 \%)$, and by direct access $(8 \%)$. Answers were most often needed immediately (76\%) and the mode of reply was verbal $(85 \%)$ in most cases. A printed literature was provided for $8 \%$ of the queries where the answers were from relevant journals. Mode of reply to queries was both verbal and written in $4 \%$ of the cases. Reply was also provided via intranet on the basis of the mode of receipt of query. The categories of questions most commonly asked were about dosage and administration (27\%) and adverse reactions (24\%), followed by queries about drug therapy (15\%). Queries were also asked on many occasions for other purposes like availability/cost, drug interactions, pharmacokinetics, pharmacodynamics, pregnancy and lactation, indication, content, contraindication, generics, drug profile, and poisoning, as shown in Table 1. Textbooks and electronic databases like MICROMEDEX were most commonly used resources (40.2\%) for answering the queries. Standard references that are listed in Table 2 were used to answer the queries. IDIS (1.5\%) and websites (5.4\%) were also used to answer queries but to a lesser extent.

Evaluation of the quality of drug information service from the receiver's perspective

Forty questionnaires (Annexure 1) were distributed to the clinicians and postgraduate trainees of different departments of the hospital for their feedback, of which, all $40(100 \%)$ responded. All of the respondents were aware of the existence of the drug information centre and 37 (92.5\%) utilized the services of the centre regularly. Among the respondents who utilized the services $35(94.6 \%)$ received the appropriate answer within the acceptable time, but two (5.4\%) of them did not receive the answer within the acceptable time. Thirty-six $(97.3 \%)$ of the respondents received the appropriate answer and one person did not get the appropriate answer. Thirtyseven $(92.5 \%)$ of the respondents were aware of the online drug information system existing in the hospital, but only 24 
Table 1

Categorization of the drug information queries

\begin{tabular}{|c|c|c|}
\hline Categorization of query & $\begin{array}{l}\text { Number of } \\
\text { queries }\end{array}$ & $\begin{array}{r}\text { Percentage of } \\
\text { queries (\%) }\end{array}$ \\
\hline \multicolumn{3}{|l|}{ Specialty } \\
\hline Medicine & 548 & 82.2 \\
\hline Others & 118 & 17.7 \\
\hline \multicolumn{3}{|l|}{ Status of the enquirer } \\
\hline Clinicians & 118 & 17.7 \\
\hline Postgraduate students & 105 & 15.7 \\
\hline Others & 14 & 2.1 \\
\hline \multicolumn{3}{|l|}{ Mode of receipt } \\
\hline Ward rounds & 471 & 70.7 \\
\hline Direct access & 48 & 7.2 \\
\hline Telephone & 135 & 20.2 \\
\hline Intranet & 13 & 1.9 \\
\hline \multicolumn{3}{|l|}{ Purpose of query } \\
\hline Better patient care & 352 & 52.8 \\
\hline Update the knowledge & 302 & 45.3 \\
\hline Education /academic & 11 & 1.66 \\
\hline \multicolumn{3}{|l|}{ Time frame to reply } \\
\hline Immediately & 507 & 76.1 \\
\hline Within 2-4 hours & 23 & 3.4 \\
\hline Within a day or two & 136 & 20.4 \\
\hline \multicolumn{3}{|l|}{ Mode of reply } \\
\hline Verbal & 565 & 84.8 \\
\hline Verbal and written & 38 & 5.7 \\
\hline Printed literature & 51 & 7.6 \\
\hline Intranet & 12 & 1.8 \\
\hline \multicolumn{3}{|l|}{ Type of query } \\
\hline Adverse drug reaction & 165 & 24.7 \\
\hline Drug therapy & 102 & 15.3 \\
\hline Dosage/administration & 180 & 27.0 \\
\hline Drug interaction & 55 & 8.2 \\
\hline Cost/availability & 68 & 10.2 \\
\hline Others & 141 & 21.1 \\
\hline \multicolumn{3}{|l|}{ References } \\
\hline Text books & 338 & 40.2 \\
\hline MICROMEDEX & 338 & 40.2 \\
\hline Websites & 36 & 5.4 \\
\hline IDIS & 10 & 1.5 \\
\hline Others & 112 & 16.8 \\
\hline
\end{tabular}

$(64.8 \%)$ of them had utilized this facility. Twenty-six $(65 \%)$ of the respondents rated the performance of the drug information centre as good, nine (22.5\%) as satisfactory and five (12.5\%) suggested that the center requires improvement in its services. Some of the suggestions to improve the performance of the drug information center were to provide information on drugs recently introduced into the market and to extend the drug
Table 2

\section{Most frequently used references}

- McEvoy GK, editor. AHFS drug information. Bethesda: American society of health system pharmacist: 2004.

- Lacy C, Armstrong LL, Lance LL, editors. Drug information handbook. 11th edition: Lexi comp: 2003- 2004.

- Parfitt K. editor. Martindale: The complete drug reference. 33rd edition. London: pharmaceutical press: 2002.

- Dukes MNG, JK Aronson. Meylers' side effects of drugs. 14th edition: 2000.

- Davies DM. Textbook of Adverse Drug Reactions: 4 th ed. New york: Oxford University Press; 1991.

- Ellenhorn MJ, Barceloux DG. Ellenhorns medical toxicology: Diagnosis and treatment of human poisoning. 2 nd ed. Baltimore: Williams and Wilkins; 1997.

- Stockley IH, editor. Drug Interactions, 3 rd ed. London; Blackwell scientific publications; 1994.

- Lawrence A Trissel. Handbook on injectable drugs, American society of health system pharmacists: 11 th edition. ASHP 2001.

Table 3

Ratings of the drug information queries in the judgmental and nonjudgmental type from the provider's perspective

\begin{tabular}{ccc}
\hline $\begin{array}{l}\text { Judgmental queries } \\
\text { No. of queries(\%) }\end{array}$ & $\begin{array}{c}\text { Nonjudgmental queries } \\
\text { No. of queries(\%) }\end{array}$ & Ratings \\
\hline $5(50)$ & $5(50)$ & 5 \\
$4(40)$ & $5(50)$ & 4 \\
$1(10)$ & 0 & 3 \\
0 & 0 & 2 \\
0 & 0 & 1 \\
\hline
\end{tabular}

information services round the clock.

Evaluation of the quality of drug information service from provider's perspective

Among the 10 judgmental queries selected, nine of them had a score of 4 or higher, as shown in Table 3. However, one of the responses were rated 1 . In the nonjudgmental type, of the 10 queries randomly selected and analyzed, five of the queries had a rating of 5 , and the other five had a rating of 4 . All the responses were rated above 4 thereby satisfying the minimum acceptable level of quality.

\section{Discussion}

Among the 666 queries received during the study period, a great percentage of the queries were from the medicine department. This could be due to the greater number of students and faculty of pharmacy practice department attending ward rounds and the vast number of drugs used in the department that necessitates the need for unbiased information. Clinicians utilized the service to a greater extent and most of the queries were for better patient care. Most of the queries required an immediate answer because it was for better patient care and hence the mode of reply was verbal, which 
was similar to the results of a study conducted by Padma GM Rao et al. ${ }^{[7]}$ Postgraduate students, interns, and nurses also availed this service, but to a lesser extent. Most queries were received during ward rounds, which could be attributed to the easy accessibility of a clinical pharmacist that prompts them to utilize the services. Number of queries received through intranet is very less, which could be due to lack of awareness of such a facility by the enquirers. Accountability of less number of queries received by direct access could be due to the location of the drug information center that is not easily feasible from the wards.

Results of the study 'Review of a drug information service in an Indian teaching hospital' by P. Nibu et al showed that drug information queries received were most commonly related to administration and dosage followed by adverse drug reactions. ${ }^{[8]}$ Similar results were observed in the present study also.

Tertiary source such as textbooks, and secondary source such as electronic databases were most commonly used resources for answering the queries. The ease of retrieval of information through textbooks explains the wide use of this tertiary source of information, and the ease of use of computer, and availability of recent and relevant information makes electronic data bases like MICROMEDEX an equally important search strategy. IDIS and websites were also used to answer queries but to a lesser extent.

Evaluation of the quality of drug information service from the receiver's perspective

Out of the 40 questionnaires that were completely filled, all of the respondents were aware of the existence of the drug information center and 37 utilized the services of the center regularly. Thirty-six of the respondents received the appropriate answer within the acceptable time and one person did not get the appropriate answer, which the enquirer said was elaborate and nonspecific to the question. Overall, most respondents rated the performance of the center as good.

Evaluation of the quality of drug information service from provider's perspective

Among the 10 judgmental queries randomly selected, five of them received a rating of 5 , four of them a rating of 4 and one was rated 3. Judgmental type of queries required the highest degree of sophistication and clinical judgment. Queries were evaluated according to predetermined, explicit, and objective criteria using separate scales for judgmental and nonjudgmental responses. Evaluation parameters pertaining to the query included various parameters like demographic data of the enquirer, background information obtained, search strategy involved, literature evaluation and response provided. After evaluation of various parameters, each query was given a rating from 1 to 5 . Rate-1 indicates that there was significant deficiency in the consultation made and rate- 5 indicates that the response was excellent, comprehensive, and well written. Of the 10 judgmental queries, nine of them had a score of
4 or higher, which means that the consultation was very good and minor problems with documentation, comprehensiveness, timeliness, writing, or other important problems existed. However, a small number of responses were rated 1 (10\%), indicating significant deficiencies with regard to documentation, comprehensiveness, timeliness or other important aspects.

In the nonjudgmental type, of the 10 queries randomly selected and analyzed, 5 of the queries had a rating of 5 , and the other 5 had a rating of 4 . All the responses were rated above 4 thereby satisfying the minimum acceptable level of quality. Nonjudgmental responses did not require extensive searching and clinical judgment and thus, the clinical pharmacist could answer such queries effectively.

Upon evaluation of the drug information queries, it was found that most of the beneficiaries of the service were the physicians and postgraduate students of the medicine department and most had utilized the services for better patient care. The analysis of the feedback questionnaire showed that most of the enquirers appreciated the quality of services provided by the drug information center. Evaluation of queries answered by the center revealed that they were within the acceptable limits of quality. However, improvement in answering the 'judgmental type' is required.

On the whole, the drug information services provided by the pharmacy practice department of the Kasturba Hospital, Manipal, caters to the need of health care professionals towards better patient care.

\section{Acknowledgments}

We thank Dr. Lincy Lal, Assistant Professor, College of Pharmacy, Texas Southern University, an adjunct faculty of our department, for giving her valuable suggestions during the preparation of the final manuscript. We would also like to acknowledge all the clinicians of Kasturba Hospital, MAHE, Manipal, for their constant support and encouragement in the drug information program. Our gratitude is also due to Mrs. Lee Baker, Pharmanet Amayeza Information Centre, South Africa, for providing the DSE guidelines necessary for evaluating the drug information service.

\section{References}

1. Amerson $A B$, Harper $G$. Introduction to the concept of medical information. In: Malone PM, Mosdell KW, Kier KL. Drug information, A Guide For Pharmacists. $2^{\text {nd }}$ ed. Mc Graw Companies 2001. p. 1-18.

2. Rosenberg JM. Drug information centers future trends. American Journal of Hospital Pharmacy 1983;40:1213-15.

3. Ramesh M, Parthasarathi G. Drug information- Role of Pharmacist. IJPE 2000;34:120-3.

4. Joshi MP. Drug information services at teaching hospitals in developing countries. Indian J Pharmacol 1998;30:1-5.

5. Barlett G, Miller J, Baler L. Evaluating the quality and effectiveness of a drug information center. Berlin DSE/WHO Seminar on Drug information centers 1997.

6. Hansen KN, Nahata MC, Parthasarathi G. Drug Information: In: SD Rajendran. A textbook of clinical pharmacy practice, essential concepts and skills. $1^{\text {st }}$ ed. Orient longman; 2004. p. 267-86.

7. Padma GM Rao, Sapna Gore, Deepa V. Evaluation of a drug information service in a South Indian teaching hospital. J Pharm Prac Res 2005;35:40-1.

8. Nibu P, Ramesh M, Parthasarathi G. Review of a drug information service in an Indian teaching hospital. Aus J Hos Pharm 2001;2:144-5. 


\section{Annexure-I}

\section{Sample form - (FEED BACK QUESTIONNAIRE)}

Department of Pharmacy Practice, Kasturba Hospital, Manipal.

1. Are you aware of the Drug information services in our hospital?

$\square$ Yes $\quad \square$ No

2. a. Have you utilized the Drug information services any time?
$\square$ Yes
$\square$ No

b. If yes, have you received the answer in time?

$\square$ Yes

$\square$ No

c. Have you received the appropriate answer?
$\square$ Yes
$\square$ No

d. If No, the reason was, the information was
$\square$ Outdated
$\square$ Too extensive
Not relevant
Others

3. a. Are you aware of the online Drug information system existing in our hospital?
$\square$ Yes
$\square$ No

b. If Yes, have you utilized this facility?
$\square$ Yes
$\square$ No

4. Do you think that the Drug information service provided by the department is useful and helps in providing better patient care?
$\square$ Yes
$\square$ No

5. How do you rate the existing Drug information system in our hospital?
$\square \operatorname{Good}$
$\square$ Satisfactory
$\square$ Needs improvement

6. Any suggestions and comments to improve the drug information services provided by the department?

Thank you for the co-operation.

Name \& Signature : 